\title{
Having it all, a scientific career and a family
}

\author{
Sandrine Etienne-Manneville investigates the molecular mechanisms underlying cell migration in health and \\ disease. She is Head of the Cell Polarity, Migration and Cancer laboratory, Director of the CNRS UMR3691 unit at \\ the Institut Pasteur, Paris, France, a professor of cell biology and a mother of four.
}

\section{Sandrine Etienne-Manneville}

Biman ecoming a researcher was my goal since I was a teenager. To achieve this I went to the United States for my master's degree, and then started a $\mathrm{PhD}$ at the Institut Cochin de Génétique Moléculaire, in Paris. During my studies I was lucky to find a partner who was reaching towards the same goals. We finished our PhDs around the same time and moved to London for our respective postdocs. There, I joined Alan Hall's laboratory where I could follow my own projects with the unconditional support of my supervisor. I loved every aspect of science. Having new ideas, designing and performing experiments to test them and obtain inspiring results was the driving force that made overcoming the long hours and stresses of the lab easy. As my, now, husband was going through the same struggles, everything made total sense.

Nearing my thirties, several of my friends already had children but, although I had always wanted a family, I had not yet taken the step. I had been warned that having a child was not the best way to get an independent position (at that time you had to be under thirty-one years of age to obtain a first CNRS position in France). I had also seen women having to harshly negotiate some extra time to finish their $\mathrm{PhD}$ because they had to stop lab work during pregnancy. When interviewing for my postdoc, I had asked my future colleagues whether having a child while in Alan's lab was an option. To my relief I learned that previous lab members had had children while working in the lab and had gone on to extremely successful research careers. My postdoc started on the best terms astrocytes turned out to be a fantastic model to study cell polarity during migration, everything seemed doable and I felt strong, confident and decided. My first paper was nearing completion when I let Alan know that I was expecting my first child. I was certainly lucky to have such a supportive supervisor, but I was extremely naïve and considered pregnancy as the hard part of having a child. The nine months flew by, with me working as much as before. Results arrived, the paper was accepted and I decided to stop working two weeks before the baby was due. In 2001, the European Molecular Biology Organisation

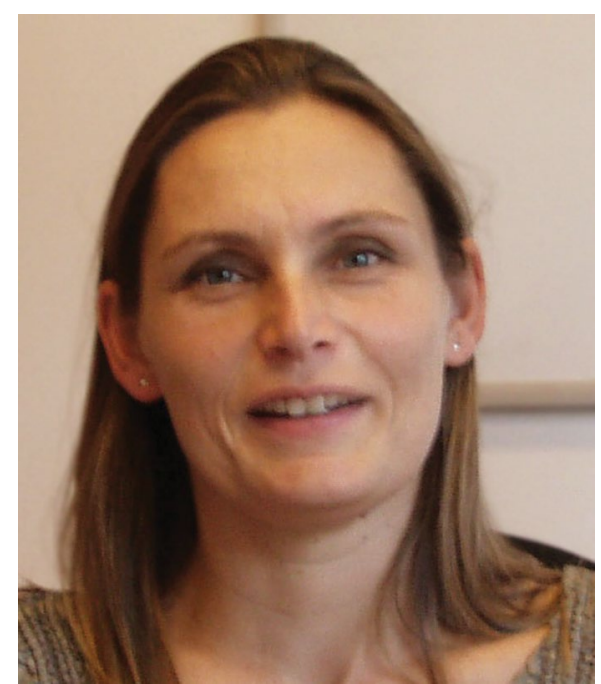

(EMBO) long-term fellowship, which was supporting my postdoc, did not allow extra time for pregnancy and I was planning to stop working for a month then go back to work as soon as possible.

My son was born 10 days early and I returned to work when he was one month old, as did my husband. However, finding a nanny for such a young child turned out to be very difficult, so we decided to take turns doing 8 hour shifts around the clock to keep working and take care of our son until he was old enough to go to child care. We would be reading or writing at home when he was asleep and doing our experiments during our individual childfree time. Although that seemed to work on paper, it did not in real life. Parenting, like science, is a full time job and the two clashed. Thinking about your child takes over the time needed to think about the latest publications; taking care of them when they are sick makes you forget your experiments; your child's sleeping schedule, when there is one, does not match a well-planned day of work and night of sleep. My life became a nightmare; not enough time for my child, not enough time for my research, not enough sleep. I started thinking that science and family were not compatible.

My turning point came when I realised that I had to give up my old way of working and adapt to the new situation, to find a new balance. Science is flexible; you can do it on your own terms. A child is much easier to take care of when you are $100 \%$ with them and not thinking about the last results you obtained. Parenthood forces you to compartmentalize, organize and stop science when you go home to be totally focused on your child. There might be overall less time for scientific goals, but the change of focus sheds a different light on the stress and competition of the research world. It has been a difficult adaptation for me and it may be easier and even obvious for others. But if you know you want it all, it is definitely worth it. A frequent question women ask is, when. Is there a perfect time (or at least a good time) to have a child during a scientific career? During your $\mathrm{PhD}$, when time is limited and you must prove to yourself and the world that you can be a good scientist? Or during your postdoc, while chasing an independent position and fighting for publications? Or as a group leader when an entire lab requires your attention and you are often away at international meetings? I now have four children. The second was perfectly planned, or so I thought, at the end of my postdoc before starting my own group back in France. The third and fourth were born when I was group leader. I do not think there is a perfect time to have a child but you need to be ready to make the time for it. Having a child might slow down research during pregnancy, and for some years after, and there might not be a way around that. But for those who desire it, building a family can ultimately bring balance in a scientific life that is extremely demanding.

Sandrine Etienne-Manneville Institut Pasteur Paris CNRS UMR3691, Cell Polarity, Migration and Cancer Unit, Paris, France.

e-mail: setienne@pasteur.fr

Published online: 28 August 2018 https://doi.org/10.1038/s41556-018-0160-X

Competing interests

The author declares no competing interests. 